\title{
NEW RESOURCES ON THE HORIZON
}

\author{
August sees the advent of our new web site, which provides free additional content and an \\ introduction to our new series of small discussion meetings, the Horizon Symposia.
}

This month, we launch a new online resource for the drug discovery community — drug discovery@nature.com (www.nature.com/drugdisc). The site, which is maintained with the sponsorship of Aventis, aims to complement our present coverage of the field by pulling together relevant content from around the Nature Publishing Group. Access to all articles posted on the site is completely free, and content will be chosen to represent the same broad editorial remit that we apply to Nature Reviews Drug Discovery — covering every aspect of the drug pipeline from chemistry to pharmacology and clinical development.

Drug discovery@nature.com contains six different types of content, as follows: regularly changing research and review articles selected from Nature Publishing Group titles; articles on careers in drug discovery; a business-update section, which will focus on pharmacoeconomic issues; Highlights, drawn from the front sections of all Nature Reviews titles, which will provide an alerting service to further papers of particular importance; and news stories, which will explore the science behind each week's main events in the pharmaceutical world. Many of these news items will be written specifically for the site, and related to this, we're delighted to welcome an additional Associate Editor, Simon Frantz, who joins the team this month with special responsibility for news coverage.

The sixth content area is dedicated to another novel "...everyone who is invited is considered a 'speaker', and will be encouraged to participate actively" keeping the meetings small and closed, but will also have the power to distribute some of the advances that each meeting brings to the wider community.

Each Horizon Symposium will address a topic of great timeliness and relevance to the drug discovery and development community, and will be focused mainly on basic science aspects of the subject. As there are already multiple meetings in all fields at which people have the chance to hear their colleagues give presentations, the main objective of the Horizon Symposia will be different - to bring together an interdisciplinary mix of scientists for a series of discussions. So more time at each meeting will be devoted to discussion than to listening to scheduled talks. Although some people will give short introductions to key points to initiate debate, everyone who is invited is considered a 'speaker', and will be encouraged to participate actively.

For those that don't come, and also for those that do, introductions to the topic will be posted on the Horizon Symposia site about six weeks before the start of each meeting. These introductions will be written in two ways. Some will be for specialist audiences, who have a detailed knowledge of the area. In keeping with our belief in making information as accessible as possible, there will also be articles written for a more broadly based scientific audience that will seek to draw people into the topic. The key questions to be raised in each discussion will also be briefly introduced, with directions to further reading on each issue.

Immediately after each symposium, highlights of the discussions will be posted on the site, giving a flavour of what occurred at the meeting. Over the following month, participants will update the introductions that they wrote to the key questions, indicating what progress was made during the discussions. For each symposium, the regular posting of articles before and after the event will hopefully tell the story of some of the most exciting developments enlivening that particular field. 